\title{
Determinants Of Antipsychotic Drugs Prescription Among Community-Living Older Adults With Dementia: A Population-Based Study Using Health Information Systems In The Lazio Region, Italy
}

This article was published in the following Dove Press journal:

Clinical Interventions in Aging

\section{Anna Maria Bargagli \\ Silvia Cascini (D) \\ Nera Agabiti \\ Ursula Kirchmayer (D) \\ Claudia Marino \\ Marina Davoli}

Department of Epidemiology, Regional Health Service Lazio Region, Rome, Italy
Introduction: Despite recommendations from associations of geriatric and psychiatry societies and warnings from drug agencies, antipsychotic (AP) drugs are frequently used to control behavioral and psychological symptoms of dementia. APs are associated with a range of potential adverse events, including increased risk of cerebrovascular events and mortality. Evidence suggests limited efficacy of APs for aggression and psychosis. Our objectives were to investigate patterns and predictors for prescription of APs among older adults with dementia residing in a large region of central Italy, and to identify patient characteristics related to typical or atypical APs prescribing.

Methods: This is a retrospective population-based cohort study using data from regional health information systems (HIS). We included dementia patients aged $\geq 65$ years residing in the Lazio region. The exposure was defined as new use vs non-use of APs. Dementia patients with incident use of APs during 2015 were followed-up from the date of first prescription to the earliest among discontinuation of use, death, or end of study (December 31, 2016).

Results: We enrolled 24,735 dementia patients, 1727 (6.7\%) new users and 23,008 non-users of APs. Forty-four percent of AP users were treated for more than 3 months, and among these about $60 \%$ received APs continuously for at least 12 months. Individuals using antidepressant or antidementia drugs had higher odds of being prescribed with APs (OR: 1.67 and OR: 1.86, respectively). Patients exposed to polypharmacy were less likely to receive APs (OR: 0.82). Cardiovascular risk factors and comorbidities were not associated with APs use. Low socioeconomic position was associated with lower odds of atypical AP prescribing (OR: 0.57).

Conclusion: The study showed that a not negligible proportion of patients had a period of AP use longer than recommended by guidelines. We identified socio-demographic and clinical factors associated with first use of APs, providing insight into prescribing practices in a community setting and useful information to address areas of potential inappropriateness.

Keywords: dementia, antipsychotics, health information systems, older adults

\section{Plain Language Summary Why Was The Study Done?}

Antipsychotic drugs (APs) are used to treat schizophrenic and bipolar disorders, but also in the management of patients with dementia to control behavioural and psychiatric disorders. As APs may cause adverse events, dementia guidelines recommend to limit their use to exceptional cases and to short periods. The present study provides a picture of AP use in dementia patients in a realworld setting, with the final aim to detect areas of potential improvement in AP prescribing.
Department of Epidemiology, Regional Health Service Lazio Region, Via Cristoforo Colombo, Rome II2 - 00147, Italy

Tel +39069972 2130

Fax +39069972 21II

Email s.cascini@deplazio.it 


\section{What Did The Researchers Do And Find?}

We used administrative healthcare data to identify older adults with dementia living in outpatient settings in a central region of Italy. For each patient, who started AP treatment in 2015-2016, we described the type of AP prescribed (conventional vs atypical) and the duration of treatment. We found that almost half of the patients treated with APs were treated longer than recommended by clinical guidelines. Dementia patients using antidepressant or anti-dementia drugs were more probable to use APs, while polypharmacy in general was associated to a lower risk of AP use. Underlying cardiovascular conditions did not influence AP prescriptions, while people in poorer socio-economic conditions had a lower chance to receive those APs considered to be more appropriate.

\section{What Do These Results Mean?}

Our results give evidence for a potential overuse of APs in dementia in central Italy. Special attention should be paid when prescribing APs to users of antidepressant or anti-dementia drugs, patients with cardiovascular problems and patients living in poor socio-economic conditions.

\section{Introduction}

The majority of people with dementia experience one or more behavioral and psychological symptoms (BPSD) at some time during their illness, in particular in the middle and later stages. ${ }^{1}$ BPSD include agitation, psychosis, aggression and restlessness, sleep disturbances and anxiety. BPSD cause distress for both, the patient and the caregiver and are associated with increased care burden and institutionalization. ${ }^{1,2}$ Since dementia prevalence is increasing and BPSD can be distressing to both patients and caregivers, there is a growing interest in the development, use and evaluation of effective interventions for BPSD.

Antipsychotic (AP) drugs are commonly prescribed for BPSD despite the evidence of their modest efficacy in treating psychosis, aggression and agitation in older patients and the significant frequency of adverse events. ${ }^{1,3-6}$ Both randomized controlled trials (RCTs) and observational studies have reported a clear association between treatment with first-generation (typical) (e.g., haloperidol and phenothiazines) and second-generation (atypical) APs (e.g., risperidone, olanzapine, quetiapine) and increased morbidity and mortality among dementia patients. ${ }^{5,7-10}$ AP use is associated with an increased risk of cardiac, orthostatic, and extrapyramidal symptoms/events, infections, falls, worsening of other symptoms of dementia, cerebrovascular events (e.g. stroke) and death.

Practice guidelines recommend person-centered, psychosocial, multidisciplinary treatment strategies as first-line approach to manage BPSD in dementia. Only when psychosocial interventions fail to adequately control severe symptoms, pharmacological treatment with APs should be considered. The recommended strategy for the use of APs in people with dementia is to start the medication at a low dosage, up-titrate the dosage slowly and to regularly review (every 3 months) the treatment with the intent to minimize treatment duration. ${ }^{11,12}$ Moreover, use of APs in dementia should be discussed with patients and caregivers and needs a cautious case-by-case assessment and careful monitoring. In most countries the only medication approved for specifically treating BPSD is risperidone, but off-label use of typical and atypical APs is common. There is sound evidence that APs are widely used for the treatment of BPSD in older people. ${ }^{5,13}$ Following the warnings on the risk associated with AP use issued since 2004 by international and national regulatory agencies, their use has decreased although prescription rates largely differ across countries and remain high, especially among institutionalized dementia patients. ${ }^{14-16}$ In Italy, despite the safety warnings, no decrease of AP use in persons with dementia has been observed between 2009 and 2012. ${ }^{14}$ Moreover, a recent report of the National Medicines Agency showed a constant increase of AP prescription in the general population from 2013 to $2017 .{ }^{17}$ Analysis of AP prescription patterns and determinants of use among persons with dementia provides important information on current treatment practices in relation to recommendations, and indicates possible needs for improvement. A number of studies focused on AP drug use among older adults with dementia residing in nursing homes while few data are available on AP prescription patterns in community-dwelling older people. The aims of the present study were to describe the patterns of AP prescription among the older adults with dementia residing in the Lazio region and to investigate determinants of first AP medication use. Factors related to typical or atypical AP prescribing were also examined. This study is based on data from regional health information systems (HIS), used to identify dementia patients, concomitant health conditions, and to track medication prescriptions.

\section{Methods}

\section{Data Sources}

We used different HIS with a comprehensive regional coverage. The Hospital Discharge Registry (HDR) routinely gathers data from all regional hospitals, including patient demographic data, admission referral source, discharge status, discharge diagnoses, procedures, and the regional code of the facility. The Drug Claims Registry (PHARM) comprises individual 
records for each drug prescription that is dispensed from public and private pharmacies, and the date of dispensing. The registry is limited to drugs dispensed to outpatients, and reimbursed by the healthcare system. Drugs are identified by the national drug register code, which is related to the Anatomical Therapeutic Chemical (ATC) classification system. Information of exemption is retrieved by the diseasespecific Ticket Exemption Registry. The Regional Health Assistance file contains the history of cancellation and registrations of the residence for each patient. Mortality endpoints were retrieved from the Regional Mortality Information System, which uses the International Classification of Disease, Ninth Revision (ICD-9-CM codes) to code cause of death. Record linkage procedures on the basis of a unique anonymous patient identifier allowed all the information to be integrated with the patient's socio-demographic characteristics, hospitalization, and date of death.

\section{Study Design And Study Population}

In this retrospective population-based cohort study, we described AP prescription patterns and determinants of first AP prescription in the Lazio region from 2015 through 2016. The study population includes individuals with dementia residing in the Lazio region (a central Italian region with about 6 million inhabitants and including Rome), and covered by the regional healthcare system.

A validated algorithm was applied to the population aged $\geq 65$ years ( $22 \%$ of residents) to identify individuals with dementia living in the region as of 31/12/2014 (enrolment date) (details in Appendix 1) ${ }^{18,19}$ Selection of the study population is described in Figure 1. Individuals with a hospital discharge for schizophrenia or bipolar disorders in the 2 years before the enrolment date were excluded from the study, as these diseases represent labeled indications for antipsychotic treatment. Moreover, since we were interested in identifying new users of APs, we excluded patients with any AP prescription in the 24-month period prior to enrolment date. Dementia patients were divided into two groups, users and non-users of APs. We defined AP users as patients with at least two prescriptions over a 1-year period. The date of first prescription was defined as index date. Patients who received only one AP prescription were classified as non-users. At last, among AP users, we excluded dementia patients who spent more than 2 months in hospital during the first 6 months of follow-up, as our data do not provide information on in-hospital drug treatment. To describe use patterns, each AP user was followed up from the index date to the earliest of the following endpoints: discontinuation of use, death, or end of study, that is December 31, 2016.

\section{Drug Utilization}

APs were identified by their Anatomical and Therapeutic Chemical (ATC) code and classified as typical (phenothiazines, butyrophenone derivatives, benzamides, zuclopentixolo, diphenylbutylpiperidine derivatives and clotiapine) and atypical (ziprasidone, clozapine, olanzapine, quetiapine, risperidone, aripripazole, amisulpride), (details on ATC codes in Appendix 2). Medication exposure was defined on the basis of defined daily doses (DDD), translating the amount of DDD available into the number of days in which the patient was treated (duration of medication use), counting one DDD per day and distributing all available DDD to the days of follow-up. In order to identify different AP treatment episodes occurring throughout the follow-up, a period of use was defined as the continuous use of typical or atypical AP, considering a period of 60 days during which the patient could claim the drug without being censored for treatment discontinuation.

\section{Socio-Demographic And Clinical Factors}

Socio-demographic characteristics (gender, age, place of residence) and information on coexisting conditions were obtained from HDR, while drug consumption was retrieved from PHARM. We used a composite areabased indicator of socioeconomic position (SEP) by census block of residence built on information derived from the 2011 census, and classified into four levels (from 1 =high to $4=$ low). We considered the following cardiovascular risk factors, identified using hospital admissions in the 2 years before the enrolment date: disorders of lipid metabolism, hypertension, ischemic heart disease (including previous cardiac revascularization), heart failure, cerebrovascular diseases (including cerebrovascular revascularization). In the same time span, we retrieved information on hospital admission for: malignant neoplasm, diabetes, chronic obstructive pulmonary disease (COPD), fluid, electrolytes and baseacid balance disorders, chronic kidney diseases, kidney and urinary tract infections, pneumonia and gastric, duodenal, peptic, gastrojejunal ulcer (details on ICD-9$\mathrm{CM}$ codes in Appendix 3). In addition, number of hospitalizations within 2 years before the date of enrolment were considered. The use of anti-dementia and antidepressant drugs was defined as at least two prescriptions in a 2-year interval before the enrolment date (details on 


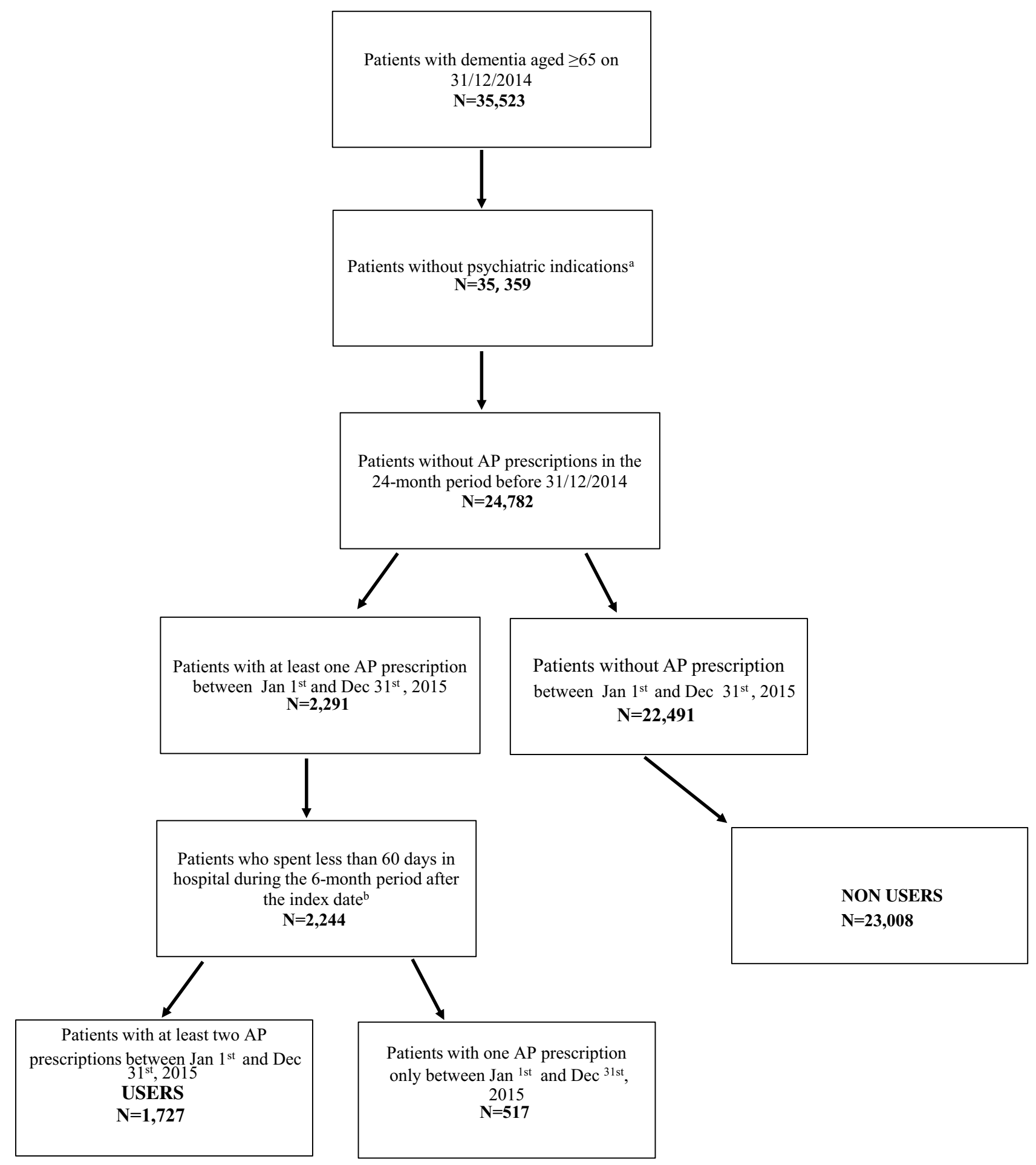

Figure I Selection of the study population.

Notes: ${ }^{a}$ Schizophrenia and bipolar disorders. 'Index date: date of first prescription from Jan Ist and Dec 3Ist, 2015.

ATC codes in Appendix 4). Moreover, all drug prescriptions claimed by the study population were retrieved. Drugs were extracted on the basis of the 4th ATC level (chemical group), and polypharmacy was defined as use of at least 6 different drugs.

\section{Statistical Analysis}

Demographic and clinical characteristics were described separately for AP users and non-users. For patients who received typical or atypical antipsychotics, we described the first period of use reporting the number of days in 
treatment, and treatment duration in term of median and interquartile range (IQR). We defined the first antipsychotic drug prescribed on the basis of ATC codes registered in the PHARM database. Switching from typical to atypical APs and vice versa occurring within the first period of use was also traced. Duration of medication use was divided into two periods, less than 3 months or above. The reason for the end of the first period of use was also described. Information on the total number of drug use periods and median interval between the first and the second treatment episode was reported. Multivariate analyses were performed using logistic regression models to study factors associated with AP use. Adjusted odds ratios (ORs) and $95 \%$ confidence intervals $(95 \% \mathrm{CI})$ were estimated controlling for all socio-demographic and clinical covariates reported above. Moreover, duration of use was plotted with Kaplan Meier curves. Utilization of drug was censored at the time of discontinuation, death or end of follow up.

\section{Results}

Figure 1 shows the process of study population selection. We identified a total of 35,359 patients with dementia aged 65 or over and alive at 31/12/2014 (enrollment date), and without previous hospitalization for schizophrenia or bipolar disorders. Thirty percent $(n=10,577)$ were prevalent users of antipsychotics. Among the remaining 24,782 patients, 2291 $(9.2 \%)$ received at least one prescription in the time span between January 1 and December 31, 2015. After application of the exclusion criteria, the final study population included 24,735 patients, 1727 (6.7\%) users and 23,008 (93.3\%) nonusers of AP drugs. Comparing users versus non-users (see Table 1), socio-demographic characteristics were rather similar but patients on treatment with AP showed a slightly lower prevalence of both cardiovascular risk factors and comorbidities and a higher rate of polypharmacy. Furthermore, more than half of patients using APs received at least two prescriptions of antidepressants $(51.4 \%)$ and anti-dementia drugs $(62.3 \%)$ within 2 years before the enrolment date. As shown in Table 2, most dementia patients were prescribed with atypical antipsychotics $(85.2 \%)$, mainly olanzapine and quetiapine. Median duration of the first period of use was 73 days (IQR 18-231). Length of first period of use was shorter than 3 months for about $56 \%$ of subjects, and, about half of these concluded drug therapy in 1 month. Among patients treated for more than 3 months $(n=769)$, about $40 \%$ percent received APs continuously for more than 24 months. Eightysix percent of subjects discontinued AP use but started again later. During the first period of use, only 134 (7.8\%) patients switched from typical to atypical AP and vice versa. Thirtytwo percent were treated only for 1 period, and $106(6.1 \%)$ had four or more drug use cycles (data not shown). Crude and adjusted ORs of first AP prescription are reported in Table 3. Men were more likely to be prescribed with APs (OR: 1.12, 95\% CI: 1.01-1.24); patients aged 65 to 74 had lower odds of receiving APs than those older than 84 years (OR: 0.87, 95\% CI: 0.74-1.02), although the estimate was not statistically significant. Cardiovascular risk factors and comorbidities did not affect the probability to receive APs. Subjects using antidepressant or anti-dementia drugs had a higher risk to receive APs, with OR: 1.67 (95\% CI: 1.51-1.85), and OR: 1.86 (95\% CI: 1.67-2.07), respectively. Patients exposed to polypharmacy were less likely to be prescribed APs (OR: 0.82, 95\% CI: 0.69-0.96). Concerning determinants of atypical vs typical AP prescriptions (see Table 4), patients residing outside the municipality of Rome as well as those with a low socio-economic position, were less likely to take atypical AP than those residing in the metropolitan area of Rome or with high SEP (OR: 0.54, 95\% CI: 0.38-0.77 and OR: 0.57, 95\% CI: 0.33-0.98, respectively). Cardiovascular risk factors and comorbidities did not influence the choice of AP type. Patients with previous use of anti-dementia drugs were at higher risk to be prescribed with atypical APs (OR: 1.49, 95\% CI: 1.11-2.00).

\section{Discussion}

This population-based study provides descriptive information on the use patterns of APs among community-dwelling patients with dementia and sheds light on factors associated with first use of AP medication. Importantly, few studies have investigated AP prescription patterns among community-dwelling dementia patients and data about physicians' prescribing behaviors in real-life practice are scarce. Prescription rates observed in our region were consistent with the estimates produced by previous studies. $^{20,21}$ A recent review ${ }^{22}$ reported significant heterogeneity in the prevalence of APs across different countries and healthcare settings. Significant differences in AP prescribing prevalence were observed between studies with community-based samples and those recruiting patients in long-term care facilities (range $7 \%-32 \%$ vs $24 \%-64 \%$ ). The pooled analysis including studies conducted in community settings between 1995 and 2013, produced a prevalence estimate of $12.3 \%$, lower than the prevalence we observed in our study, suggesting that in the Lazio region use of APs among patients with dementia is quite frequent. 
Table I Demographic And Clinical Characteristics Of Antipsychotic Users And Non-Users. Lazio Region, 31/12/2014

\begin{tabular}{|c|c|c|c|c|}
\hline & \multirow{2}{*}{ 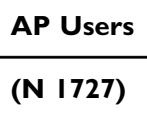 } & \multirow{2}{*}{$\begin{array}{l}\text { Non-AP Users } \\
(\mathbf{N} 23,008)\end{array}$} & \multirow[t]{3}{*}{ p-Value } & \multirow{2}{*}{$\begin{array}{l}\text { Total } \\
(\mathbf{N} 24,735)\end{array}$} \\
\hline & & & & \\
\hline & $\%$ & $\%$ & & $\mathbf{N}$ \\
\hline \multicolumn{5}{|l|}{ Gender } \\
\hline Male & 34.8 & 34.1 & 0.613 & 9360 \\
\hline Female & 65.3 & 65.9 & & 18,055 \\
\hline \multicolumn{5}{|l|}{ Age (in years) } \\
\hline $65-74$ & 14.5 & 14.9 & 0.360 & 4009 \\
\hline $75-84$ & 53.4 & 51.6 & & 14,088 \\
\hline $85+$ & 32.1 & 33.5 & & 9318 \\
\hline \multicolumn{5}{|l|}{ Residence } \\
\hline Municipality of Rome & 57.2 & 54.4 & 0.051 & 15,018 \\
\hline Other municipalities in the province of Rome & 18.9 & 21.0 & & 5701 \\
\hline Other provinces of the Lazio region & 23.9 & 24.6 & & 6696 \\
\hline \multicolumn{5}{|l|}{ Socio-economic position } \\
\hline I (High) & 14.5 & 12.7 & 0.242 & 3515 \\
\hline 2 & 24.4 & 24.5 & & 6769 \\
\hline 3 & 25.9 & 26.0 & & 7139 \\
\hline 4 (Low) & 15.8 & 16.6 & & 4486 \\
\hline not reported & 19.3 & 20.3 & & 5506 \\
\hline \multicolumn{5}{|l|}{ Number of hospitalizations } \\
\hline \multicolumn{5}{|l|}{ ( 2 years before date of enrolment) } \\
\hline 0 & 57.3 & 56.0 & 0.098 & 15,203 \\
\hline 1 & 25.6 & 24.8 & & 6853 \\
\hline 2 & 10.4 & 10.7 & & 2993 \\
\hline $3+$ & 6.8 & 8.4 & & 2366 \\
\hline \multicolumn{5}{|l|}{ Cardiovascular risk factors ${ }^{a}$} \\
\hline Disorders of lipid metabolism & 3.1 & 2.6 & 0.217 & 697 \\
\hline Hypertension & 15.9 & 17.0 & 0.224 & 4678 \\
\hline Ischemic heart disease ${ }^{b}$ & 4.7 & 6.1 & 0.019 & 1686 \\
\hline Heart failure & 3.7 & 4.6 & 0.084 & 1300 \\
\hline Cerebrovascular diseases $^{c}$ & 15.1 & 16.2 & 0.209 & 4493 \\
\hline \multicolumn{5}{|l|}{ Coexisting comorbidities $^{a}$} \\
\hline Malignant neoplasm & 4.1 & 4.3 & 0.649 & 1181 \\
\hline Diabetes & 6.0 & 7.8 & 0.006 & 2148 \\
\hline COPD & 4.7 & 6.3 & 0.008 & 1734 \\
\hline Fluid, electrolytes and base-acid balance disorders & 3.1 & 3.3 & 0.699 & 959 \\
\hline Chronic kidney diseases & 3.8 & 5.0 & 0.034 & 1367 \\
\hline Pneumonia & 2.1 & 3.2 & 0.010 & 903 \\
\hline Disease of the blood and blood-forming organs & 5.5 & 6.3 & 0.196 & 1786 \\
\hline Fracture of neck of femur & 4.0 & 3.4 & 0.139 & 1003 \\
\hline Depression & 0.4 & 0.3 & 0.467 & 93 \\
\hline $\begin{array}{l}\text { Polypharmacy (use of } 6+\text { drugs), ATC } 4^{\circ} \text { level } \\
\text { Other psychotropic medications }{ }^{\mathrm{a}}\end{array}$ & 88.8 & 88.9 & & 21,987 \\
\hline Antidepressant drugs & 51.4 & 36.9 & $<0.001$ & 10,614 \\
\hline Anti-dementia drugs & 62.3 & 45.6 & $<0.001$ & 12,710 \\
\hline
\end{tabular}

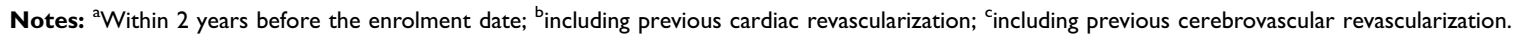


Table 2 Description Of The First Period Of AP Use During 2015

\begin{tabular}{|c|c|c|}
\hline & \multirow{2}{*}{\multicolumn{2}{|c|}{$\begin{array}{l}\text { All } \\
\text { Antipsychotic } \\
\text { Users }\end{array}$}} \\
\hline & & \\
\hline & \multicolumn{2}{|c|}{$(N=1727)$} \\
\hline & \multicolumn{2}{|c|}{ Median (IQR) } \\
\hline \multirow[t]{2}{*}{ Coverage in days } & \multicolumn{2}{|c|}{$73(18-231)$} \\
\hline & $\mathbf{N}$ & $\%$ \\
\hline \multicolumn{3}{|l|}{ Antipsychotic classification } \\
\hline Typical & 256 & 14.8 \\
\hline Phenothiazines & 44 & 17.2 \\
\hline Butyrophenone derivatives & 178 & 69.5 \\
\hline Thioxanthene derivatives & 1 & 0.4 \\
\hline Diphenylbutylpiperidine derivatives & I & 0.4 \\
\hline Clotiapine & 19 & 7.4 \\
\hline Benzamides excl amisulpride & 12 & 4.7 \\
\hline Atypical & $|47|$ & 85.2 \\
\hline Olanzapine, quetiapine & 1420 & 82.2 \\
\hline Amisulpride & 4 & 0.2 \\
\hline Other antipsychotics & 47 & 2.3 \\
\hline \multicolumn{3}{|c|}{$\begin{array}{l}\text { Switch to another AP class within period of } \\
\text { use }\end{array}$} \\
\hline No & 1593 & 92.2 \\
\hline Yes, starting with: & 134 & 7.8 \\
\hline Typical & 64 & 47.8 \\
\hline Atypical & 70 & 52.2 \\
\hline \multicolumn{3}{|l|}{ Period of use } \\
\hline Up to 3 months & 958 & 55.5 \\
\hline I month & 526 & 54.9 \\
\hline 2 months & 262 & 27.3 \\
\hline 3 months & 170 & 17.7 \\
\hline More than 3 months & 769 & 44.6 \\
\hline 4-6 months & 237 & 30.8 \\
\hline 7-24 months & 242 & 31.5 \\
\hline$>24$ months & 300 & 39.0 \\
\hline \multicolumn{3}{|l|}{ End of period due to: } \\
\hline Discontinuation & 1479 & 85.6 \\
\hline Death & 3 & 0.1 \\
\hline Study end & 245 & 11.9 \\
\hline
\end{tabular}

Abbreviations: AP, antipsychotic; IQR, interquartile range.

Furthermore, a study carried out in Italy and in the UK, using data from a sample of General Practitioners, assessed the effects of warnings issued by national agencies on the use of APs. ${ }^{14}$ Between 2009 and 2012, the authors observed a decline in both atypical and typical AP prescription rates in the UK but not in Italy where prescription rates increased from $11 \%$ to $18 \%$ and from $9 \%$ to $11 \%$ for atypical and typical AP, respectively.

This study showed that in the Lazio region long-term treatment of dementia patients in community settings with AP is rather frequent. We found that about $45 \%$ of patients were treated with APs for 3 months or more. These results raise questions about the appropriateness of duration of use. Actually, since APs are associated with significant serious adverse effects including hip fracture, pneumonia, stroke, and death, ${ }^{5,23,24}$ this practice might not be in line with current guidelines that recommend time-limited use of APs with regular reviews every 3 months. ${ }^{11,12}$ Koponen et al estimated $57 \%$ of long-term (at least 365 days) users among Finnish patients with clinically verified Alzheimer's disease, ${ }^{25}$ while in a study conducted in British Columbia, $14 \%$ of individuals with dementia were classified as long-term users (more than 90 days). ${ }^{26}$ AP long-term (more than 85 days) exposure in community-dwelling patients with Alzheimer's disease and related dementias living in the South-East of France was also frequent (about 30\%). ${ }^{21}$ Prevalence of long-term use in our study is quite in line with findings of previous studies, although comparisons among studies are impaired by different contexts as well as different definitions of long-term use. Considering that AP prevalence and longterm use in nursing homes reported by other authors ${ }^{27,28}$ are even higher than in our study, we retain that AP prescription patterns need to be carefully monitored in both settings. Moreover, if necessary, the clinical practice should be reviewed through audit processes and providing support to caregivers managing patients with complex symptoms and needs.

Although different studies have suggested gender-based variations in AP prescription patterns among individuals with dementia, the association between AP use and gender is still controversial. Some studies found that women were more frequently prescribed APs than men. ${ }^{29-31}$ However, consistent with findings from some other studies, ${ }^{16,32,33}$ in our study men were more likely than women to be prescribed with APs. A recent review by Trenaman et al ${ }^{34}$ observed that men and women tend to use more antipsychotics dependent on their living environment, women in the community and men in long-term care facilities. The review concluded further research is required to obtain more solid evidence and understand how gender differences can be used to improve medication use among patients with dementia. 
Table 3 Crude And Adjusted ORs And 95\% Cls Of First AP Prescription Among Dementia Patients In The Lazio Region

\begin{tabular}{|c|c|c|c|c|c|c|c|c|}
\hline Gender & \multirow{2}{*}{$\begin{array}{l}\mathbf{N} \\
600\end{array}$} & \multirow{2}{*}{$\begin{array}{l}\text { OR } \\
0.98\end{array}$} & \multicolumn{2}{|c|}{$95 \% \mathrm{Cl}$} & \multirow{2}{*}{$\begin{array}{l}\mathbf{O R}_{\mathbf{a d j}} \\
1.12\end{array}$} & \multicolumn{2}{|c|}{$95 \% \mathrm{Cl}$} & \multirow{2}{*}{$\begin{array}{l}\boldsymbol{p} \text {-value } \\
0.039\end{array}$} \\
\hline Male & & & 0.90 & 1.07 & & 1.01 & 1.24 & \\
\hline \multicolumn{9}{|l|}{ Age (years) } \\
\hline $85+$ & 555 & 1.00 & & & 1.00 & & & \\
\hline $65-74$ & 250 & 1.02 & 0.87 & 1.19 & 0.87 & 0.74 & 1.02 & 0.094 \\
\hline $75-84$ & 922 & 1.08 & 0.97 & 1.20 & 0.95 & 0.85 & 1.06 & 0.355 \\
\hline \multicolumn{9}{|l|}{ Residence } \\
\hline Municipality of Rome & 988 & 1.00 & & & 1.00 & & & \\
\hline Other municipalities in the province of Rome & 327 & 0.86 & 0.75 & 0.98 & 0.88 & 0.77 & 1.00 & 0.054 \\
\hline Other provinces of the Lazio region & 412 & 0.92 & 0.82 & 1.04 & 0.94 & 0.83 & 1.07 & 0.358 \\
\hline \multicolumn{9}{|l|}{ Socio-economic position } \\
\hline I (High) & 251 & 1.00 & & & 1.00 & & & \\
\hline 2 & 421 & 0.99 & 0.98 & 1.00 & 0.89 & 0.76 & 1.05 & 0.166 \\
\hline 3 & 448 & 0.99 & 0.98 & 1.00 & 0.92 & 0.78 & 1.08 & 0.315 \\
\hline 4 (Low) & 273 & 0.99 & 0.98 & 1.00 & 0.89 & 0.74 & 1.06 & 0.191 \\
\hline Not reported & 334 & 0.99 & 0.98 & 1.00 & 0.90 & 0.75 & 1.07 & 0.222 \\
\hline \multicolumn{9}{|l|}{ Number of hospitalizations } \\
\hline \multicolumn{9}{|l|}{ ( 2 years before date of enrolment) } \\
\hline 0 & 989 & 1.00 & & & 1.00 & & & \\
\hline 1 & 442 & 1.01 & 0.90 & 1.13 & 1.11 & 0.97 & 1.28 & 0.139 \\
\hline 2 & 179 & 0.94 & 0.80 & 1.11 & 1.11 & 0.90 & 1.37 & 0.347 \\
\hline $3+$ & 117 & 0.79 & 0.64 & 0.96 & 0.99 & 0.75 & 1.32 & 0.969 \\
\hline \multicolumn{9}{|l|}{ Cardiovascular risk factors } \\
\hline \multicolumn{9}{|l|}{ ( 2 years before date of enrolment) } \\
\hline Disorders of lipid metabolism & 53 & 1.20 & 0.90 & 1.59 & 1.23 & 0.91 & 1.66 & 0.185 \\
\hline Hypertension & 274 & 0.92 & 0.80 & 1.05 & 1.04 & 0.88 & 1.23 & 0.622 \\
\hline Ischemic heart disease ${ }^{a}$ & 81 & 0.76 & 0.60 & 0.96 & 0.89 & 0.69 & 1.14 & 0.357 \\
\hline Heart failure & 64 & 0.80 & 0.62 & 1.03 & 1.05 & 0.79 & 1.40 & 0.723 \\
\hline Cerebrovascular diseases $^{\mathrm{b}}$ & 260 & 0.91 & 0.80 & 1.05 & 1.06 & 0.90 & 1.25 & 0.506 \\
\hline \multicolumn{9}{|l|}{ Coexisting comorbidities } \\
\hline \multicolumn{9}{|l|}{ ( 2 years before date of enrolment) } \\
\hline Malignant neoplasm & 71 & 0.94 & 0.74 & 1.21 & 0.99 & 0.76 & 1.29 & 0.955 \\
\hline Diabetes & 103 & 0.75 & 0.61 & 0.92 & 0.84 & 0.67 & 1.05 & 0.129 \\
\hline COPD & 81 & 0.73 & 0.58 & 0.92 & 0.90 & 0.70 & 1.16 & 0.432 \\
\hline Fluid, electrolytes and base-acid balance disorders & 54 & 0.94 & 0.71 & 1.25 & 1.19 & 0.89 & 1.60 & 0.247 \\
\hline Chronic kidney diseases & 66 & 0.76 & 0.59 & 0.98 & 0.94 & 0.71 & 1.24 & 0.667 \\
\hline Pneumonia & 36 & 0.64 & 0.46 & 0.90 & 0.76 & 0.53 & 1.09 & 0.133 \\
\hline Disease of the blood and blood-forming organs & 95 & 0.86 & 0.70 & 1.07 & 0.98 & 0.78 & 1.24 & 0.886 \\
\hline Fracture of neck of femur & 70 & 1.21 & 0.94 & 1.55 & 1.28 & 0.98 & 1.68 & 0.070 \\
\hline Depression & 7 & 1.33 & 0.61 & 2.90 & 1.23 & 0.56 & 2.71 & 0.611 \\
\hline \multicolumn{9}{|l|}{ Drug use (at least 2 prescriptions) } \\
\hline \multicolumn{9}{|l|}{ ( 2 years before date of enrolment) } \\
\hline Antidepressant drugs & 887 & 1.80 & 1.63 & 1.99 & 1.67 & 1.51 & 1.85 & $<0.0001$ \\
\hline Anti-dementia drugs & 1076 & 1.97 & 1.78 & 2.18 & 1.86 & 1.67 & 2.07 & $<0.0001$ \\
\hline Polypharmacy (use of $6+$ drugs), ATC $4^{\circ}$ level & 1534 & 0.99 & 0.85 & 1.16 & 0.82 & 0.69 & 0.96 & 0.014 \\
\hline
\end{tabular}

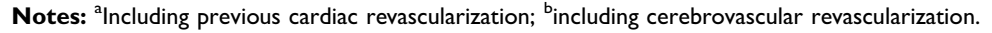

Abbreviations: $\mathrm{OR}$, odds ratio; $\mathrm{Cl}$, confidence intervals; COPD, chronic obstructive pulmonary disease; AP, antipsychotic. 
Table 4 Crude And Adjusted OR And 95\% Cls Of Atypical Vs Typical AP Prescriptions Among Dementia Patients In The Lazio Region

\begin{tabular}{|c|c|c|c|c|c|c|c|c|}
\hline \multirow{2}{*}{ Gender } & \multirow{2}{*}{$\begin{array}{l}\mathbf{N} \\
523\end{array}$} & \multirow{2}{*}{$\begin{array}{l}\text { OR } \\
0.78\end{array}$} & \multicolumn{3}{|c|}{ 95\% Cl } & \multirow{2}{*}{$\begin{array}{l}\mathbf{O} \mathbf{R}_{\mathbf{a d j}} \\
0.97\end{array}$} & \multirow{2}{*}{$\begin{array}{l}95 \% \mathrm{Cl} \\
1.79\end{array}$} & \multirow{2}{*}{$\begin{array}{l}p \text {-value } \\
0.078\end{array}$} \\
\hline & & & 0.58 & 1.04 & 1.32 & & & \\
\hline \multicolumn{9}{|l|}{ Age (years) } \\
\hline $85+$ & 468 & 1.00 & & & 1.00 & & & \\
\hline $65-74$ & 224 & 1.60 & 1.00 & 2.55 & 1.32 & 0.80 & 2.16 & 0.273 \\
\hline $75-84$ & 779 & 1.01 & 0.76 & 1.35 & 0.87 & 0.64 & 1.19 & 0.392 \\
\hline \multicolumn{9}{|l|}{ Residence } \\
\hline Municipality of Rome & 860 & 1.00 & & & 1.00 & & & \\
\hline Other municipalities in the province of Rome & 261 & 0.58 & 0.42 & 0.82 & 0.54 & 0.38 & 0.77 & 0.001 \\
\hline Other provinces of the Lazio region & 350 & 0.84 & 0.60 & 1.17 & 0.78 & 0.55 & 1.10 & 0.162 \\
\hline \multicolumn{9}{|l|}{ Socio-economic position } \\
\hline I (High) & 227 & 1.00 & & & 1.00 & & & \\
\hline 2 & 347 & 0.92 & 0.87 & 0.98 & 0.50 & 0.30 & 0.82 & 0.006 \\
\hline 3 & 381 & 0.95 & 0.90 & 1.01 & 0.63 & 0.38 & 1.05 & 0.078 \\
\hline 4 (Low) & 228 & 0.93 & 0.88 & 0.99 & 0.57 & 0.33 & 0.98 & 0.042 \\
\hline Not reported & 288 & 0.96 & 0.90 & 1.02 & 0.76 & 0.44 & 1.31 & 0.318 \\
\hline \multicolumn{9}{|l|}{ Number of hospitalizations } \\
\hline \multicolumn{9}{|l|}{ ( 2 years before date of enrolment) } \\
\hline 0 & 850 & & & & 1.00 & & & \\
\hline I & 377 & 0.95 & 0.69 & 1.30 & 0.99 & 0.67 & 1.47 & 0.969 \\
\hline 2 & 150 & 0.84 & 0.55 & 1.31 & 0.92 & 0.52 & 1.60 & 0.756 \\
\hline $3+$ & 94 & 0.67 & 0.41 & 1.09 & 0.66 & 0.31 & 1.37 & 0.260 \\
\hline \multicolumn{9}{|l|}{ Cardiovascular risk factors } \\
\hline \multicolumn{9}{|l|}{ ( 2 years before date of enrolment) } \\
\hline Disorders of lipid metabolism & 47 & 1.37 & 0.58 & 3.25 & 1.33 & 0.53 & 3.36 & 0.540 \\
\hline Hypertension & 230 & 0.89 & 0.63 & 1.27 & 1.16 & 0.73 & 1.84 & 0.525 \\
\hline Ischemic heart disease ${ }^{a}$ & 72 & 1.41 & 0.70 & 2.86 & 1.92 & 0.88 & 4.18 & 0.100 \\
\hline Heart failure & 51 & 0.67 & 0.36 & 1.25 & 0.60 & 0.29 & 1.25 & 0.170 \\
\hline Cerebrovascular diseases $^{\mathrm{b}}$ & 218 & 0.89 & 0.62 & 1.27 & 1.00 & 0.63 & 1.58 & 0.995 \\
\hline \multicolumn{9}{|l|}{ Coexisting comorbidities } \\
\hline \multicolumn{9}{|l|}{ ( 2 years before date of enrolment) } \\
\hline Malignant neoplasm & 58 & 0.76 & 0.41 & 1.42 & 0.88 & 0.45 & 1.74 & 0.722 \\
\hline Diabetes & 82 & 0.66 & 0.40 & 1.09 & 0.75 & 0.42 & 1.33 & 0.326 \\
\hline COPD & 67 & 0.82 & 0.46 & 1.49 & 1.01 & 0.52 & 1.98 & 0.968 \\
\hline Fluid, electrolytes and base-acid balance disorders & 46 & 1.00 & 0.46 & 2.15 & 1.27 & 0.56 & 2.91 & 0.570 \\
\hline Chronic kidney diseases & 58 & 1.27 & 0.60 & 2.70 & 1.64 & $0.7 \mathrm{I}$ & 3.79 & 0.251 \\
\hline Pneumonia & 30 & 0.87 & 0.36 & 2.10 & 0.86 & 0.33 & 2.24 & 0.757 \\
\hline Disease of the blood and blood-forming organs & 81 & 1.01 & 0.56 & 1.80 & 1.26 & 0.64 & 2.47 & 0.499 \\
\hline Fracture of neck of femur & 53 & 0.52 & 0.30 & 0.92 & 0.57 & 0.30 & 1.09 & 0.089 \\
\hline Depression & 6 & 1.04 & 0.12 & 8.71 & 1.08 & 0.12 & 10.04 & 0.943 \\
\hline \\
\hline \multicolumn{9}{|l|}{ ( 2 years before date of enrolment) } \\
\hline Antidepressant drugs & 768 & 1.26 & 0.97 & 1.64 & 1.27 & 0.96 & 1.68 & 0.097 \\
\hline Anti-dementia drugs & 941 & 1.59 & 1.22 & 2.08 & 1.49 & I.II & 2.00 & 0.009 \\
\hline Polypharmacy (use of $6+$ drugs), ATC $4^{\circ}$ level & 1306 & 0.97 & 0.64 & $\mathrm{I} .48$ & 0.89 & 0.57 & 1.40 & 0.625 \\
\hline
\end{tabular}

Notes: ${ }^{a}$ Including previous cardiac revascularization; ${ }^{b}$ including cerebrovascular revascularization.

Abbreviations: OR, odds ratio; $\mathrm{Cl}$, confidence intervals; COPD, chronic obstructive pulmonary disease; AP, antipsychotic. 
We did not find any association between age and AP prescription while previous studies showed that overall antipsychotic use is significantly lower for older patients. ${ }^{16,35,36}$

To investigate the role of SEP on AP treatment, we used an area-based indicator constructed using data from the 2011 census and attributed to small geographic areas (census tract of residence). In our context, SEP did not result to be a determinant of AP use. Few studies investigated the impact of socio-economic factors on AP prescription rates among dementia patients using individual indicators. Lower education and lower income were found to be associated with a higher use of APs. ${ }^{16,26,37}$ Similar findings have been observed using area-based SEP indicators, and individuals living in rural or low-income areas were more likely to receive APs. ${ }^{38}$ Different hypotheses have been proposed to explain the observed variation. Caregivers of highly educated patients may have the skills to appropriately manage BPSD and, considering safety concerns about AP use, may express a preference for non-pharmacological approaches. On the other side, physicians may be more willing to discuss alternative treatments for BPSD with persons with higher health literacy. Our findings support the evidence of at least some heterogeneity in prescriptive patterns in relation to socio-demographic characteristics that, in our opinion, deserves more attention.

It is well documented that people with dementia have a higher burden of comorbidity and polypharmacy than those without dementia. ${ }^{39-41}$ In our study, while polypharmacy was identified as a protective factor for AP prescribing, hospitalization for both cardiovascular risk factors and comorbid conditions did not affect the probability to receive an AP. Cerebrovascular diseases and cardiovascular risk factors (hypertension, ischemic heart diseases, atrial fibrillation) represent limiting conditions for antipsychotics prescription to dementia patients. ${ }^{11,12}$ Among patients with cardiovascular or cerebrovascular diseases, prescription of APs should be restricted to those severely distressed and should be limited to short periods. A recent study found that dementia patients with a history of hypertension, stroke, renal/hepatic dysfunction or diabetes were less prescribed with APs. ${ }^{30}$ Actually, in our study polypharmacy is associated with a lower odds of AP prescription. This finding makes sense considering that polypharmacy may be reflective of the overall severity of the underlying comorbid conditions. However, our results suggest that more attention should be paid to the evaluation of individual risk/benefit assessments in this frail, older population. Patients with previous use of antidepressant and anti-dementia drugs were treated with significantly more APs. The association between APs and anti-dementia drug use is possibly explained by severity of dementia.

Atypical APs, in particular olanzapine and quetiapine, were most frequently prescribed for older patients with dementia in the Lazio region. Preferential use of atypical agents can be partially attributed to the perceived superior safety and tolerability and similar efficacy of atypical agents compared to typical ones. ${ }^{41}$

Studies investigating factors associated with typical or atypical AP prescribing in real-world practice settings are scarce. In our study, there were no significant differences in clinical characteristics between patients prescribed atypical vs typical APs, unless patients in treatment with antidementia and antidepressant drugs were more likely to take atypical AP medications. Among socio-demographic factors, lower SEP and residence outside the metropolitan area of Rome were associated with lower odds of receiving atypical AP agents, emphasizing a geographical heterogeneity and social disparities in AP prescribing in patients with dementia-related BPSD.

There are several strengths in this study. Firstly, to our knowledge, this is the first study analyzing the determinants of typical/atypical AP utilization using administrative databases. This offered the opportunity to study a large population-based cohort, controlling for a large number of potential confounding factors. Second, this large observational study included patients who would not have been considered in clinical trials and thus allowed us to analyzed real-world dementia drug treatment patterns. Third, we used a validated algorithm to identify people with dementia. The limitations of the current study are mainly related to the observational design. Our analyses were based on drug prescriptions rather than actual use of APs. We cannot be certain that every person prescribed with an AP really took the drug or even the prescribed dose. PHARM contains all prescription reimbursed but over-the-counter drugs and drugs dispensed during hospital admission were not included, so there could be an underestimate of use. However, to avoid this we excluded all patients hospitalized for more than 2 months within 6 months of follow-up. Additionally, although we included a large variety of socio-demographic factors and comorbid conditions, we cannot exclude the possible effect of unmeasured confounding on our results. 
Concerning the identification of concomitant conditions, using the HDR as unique source of information, we might have been limited in identifying cardiovascular risk factors, such as hypertension or disorders of lipid metabolism. Finally, administrative database do not provide data on severity of dementia, thus if there is no information on the motivation for a prolonged AP therapy or the efficacy of the treatment, i.e. whether symptoms remained stable or worsened.

Considering the results obtained in the present study for the Lazio Region, we can suppose that despite safety concerns and modest efficacy, AP use has remained frequent among persons with dementia. Additionally, the length of AP therapy in our study appeared longer than recommended by guidelines, largely exceeding 3 months for a not negligible fraction of the study population. Anyway, we cannot exclude that our algorithm specifically selects a sub-population of patients with more severe symptoms requiring prolonged treatment with APs.

\section{Conclusion}

We observed that a still large amount of dementia patients are treated with APs and a not negligible proportion of them has a period of use longer than recommended by guidelines. These findings deserve further investigation to ascertain whether older adults with dementia are adequately treated or whether the proportion of those taking antipsychotics can be further reduced. This work identified socio-demographic and clinical factors associated with first use of AP medications, providing insight into prescribing practices in the community setting and suggesting targets to address to improve the quality of care for older adults living with dementia. Finally, although some limitations must be considered, our study highlights the importance of HIS to describe and monitor healthcare services delivery and to identify areas of potential inappropriateness.

\section{Ethics}

The Department of Epidemiology, Regional Health Service Lazio Region, is the regional referral center for epidemiological research and has full access to anonymized health information systems. Consent was not necessary because the authors used data already collected at the beginning of the study and the data were analyzed anonymously through a standardized methodology according to the national privacy law (national legislative decree on privacy policy n. 196/30 June 2003). Individuals cannot be identified directly or through identifiers and results are shown in aggregate form.

\section{Data Availability}

Data related to the findings reported in our manuscript are available to all interested researchers upon request because of stringent legal restrictions regarding the privacy policy on personal information in Italy (national legislative decree on privacy policy n. 196/30 June 2003). For these reasons our dataset cannot be made available on public data deposition. All interested researchers can contact the following persons to request the data: Nera Agabiti, Department of Epidemiology, Lazio Regional Health Service, Rome, Italy, E-mail: n.agabiti@deplazio.it; Damiano Lanzi, Department of Epidemiology, Lazio Regional Health Service, Rome, Italy, E-mail: d.lanzi@deplazio.it.

\section{Author Contributions}

Anna Maria Bargagli, Silvia Cascini, Nera Agabiti, Marina Davoli contributed to conception and design of the study. Anna Maria Bargagli, Silvia Cascini and Ursula Kirchmayer wrote the protocol. Anna Maria Bargagli and Claudia Marino managed the literature searches and analyses. Silvia Cascini performed the statistical analysis. All authors contributed to the interpretation of the results. Anna Maria Bargagli, Silvia Cascini wrote the first draft of the manuscript. All authors took part in revising the article critically for important intellectual content; gave final approval of the version to be published; and agree to be accountable for all aspects of the work.

\section{Funding}

This study was conducted without additional financial support from any external research bodies.

\section{Disclosure}

The authors report no conflicts of interest in this work.

\section{References}

1. Greenblatt HK, Greenblatt DJ. Use of antipsychotics for the treatment of behavioral symptoms of dementia. J Clin Pharmacol. 2016;56 (9):1048-1057. doi: $10.1002 / j c p h .731$

2. Azermai M, Petrovic M, Elseviers MM, Bourgeois J, Van Bortel LM, Vander Stichele RH. Systematic appraisal of dementia guidelines for the management of behavioural and psychological symptoms. Ageing Res Rev. 2012;11(1):78-86. doi:10.1016/j.arr.2011.07.002

3. Ballard C, Waite J, Birks J. The effectiveness of atypical antipsychotics for the treatment of aggression and psychosis in Alzheimer's disease. Cochrane Database Sys Rev. 2006;(Issue 1):Art. N.: CD003476. doi:10.1002/14651858.CD003476.pub2.

4. Vasudev A, Shariff SZ, Liu K, et al. Trends in psychotropic dispensing among older adults with dementia living in long-term care facilities: 2004-2013. Am J Geriatr Psychiatry. 2015;23(12):1259-1269. doi:10.1016/j.jagp.2015.07.001 
5. Tampi RR, Tampi DJ, Balachandran S, Srinivasan S. Antipsychotic use in dementia: a systematic review of benefits and risks from metaanalyses. Ther Adv Chron Dis. 2016;7:229-245. doi:10.1177/ 2040622316658463

6. Ivers NM, Taljaard M, Giannakeas V, Reis C, Williams E, Bronskill S. Public reporting of antipsychotic prescribing in nursing homes: population-based interrupted time series analyses. BMJ Qual Saf. 2019;28(2):121-131. doi:10.1136/bmjqs-2018-007840

7. Wang PS, Schneeweiss S, Avorn J, et al. Risk of death in elderly users of conventional vs. Atypical Antipsychotic Medications. N Engl J Med. 2005;353(22):2335-2341. doi:10.1056/NEJMoa052827

8. Jalbert JJ, Eaton CB, Miller SC, Lapane KL. Antipsychotic use and the risk of hip fracture among older adults afflicted with dementia. $J$ Am Med Die Assoc. 2010;11(2):120-127. doi:10.1016/j. jamda.2009.10.001

9. Maust DT, Kim HM, Seyfried LS, et al. Antipsychotics, other psychotropics, and the risk of death in patients with dementia: number needed to harm. JAMA Psychiatry. 2015;72(5):438-445. doi:10.1001/ jamapsychiatry.2014.3018

10. Sacchetti E, Turrina C, Valsecchi P. Cerebrovascular accidents in elderly people treated with antipsychotic drugs: a systematic review. Drug Saf. 2010;33(4):273-288. doi:10.2165/11319120-000000000-00000

11. National Institute for Health and Care Excellence (NICE) Guidelines. Dementia: assessment, management and support for people living with dementia and their caregivers guideline [NG97]. Published June 2018.

12. Reus VI, Fochtmann LJ, Eyler AE, et al. The American Psychiatric Association practice guideline on the use of antipsychotics to treat agitation or psychosis in patients with dementia. Am J Psychiatry. 2016;173(5):543-546. doi:10.1176/appi.ajp.2015.173501

13. de Mauleon A, Sourdet S, Renom-Guiteras A, et al. Associated factors with antipsychotic use in long-term institutional care in eight European countries: results from the right time place care study. J Am Med Dir Assoc. 2014;15(11):812-818. doi:10.1016/j. jamda.2014.06.015

14. Sultana J, Fontana A, Giorgianni F, et al. The effect of safety warnings on antipsychotic drug prescribing in elderly persons with dementia in the United Kingdom and Italy: a population-based study. CNS Drugs. 2016;30(11):1097-1109. doi:10.1007/s40263-016-0366-Z

15. Hessmann P, Dodel R, Baum E, et al. Antipsychotic treatment of community-dwelling and institutionalised patients with dementia in Germany. Int $J$ Psychiatry Clin Pract. 2018;22(3):232-239. doi:10.1080/13651501.2017.1414269

16. Tifratene K, Manera V, Fabre R, et al. Antipsychotic prescribing for Alzheimer's disease and related disorders in specialized settings from 2010 to 2014 in France: a repeated cross-sectional study. Alzheimers Res Ther. 2017;9(1):34-44. doi:10.1186/s13195-017-0256-8

17. Italian Medicines Agency. The medicines utilization monitoring centre. National Report on Medicines use in Italy. 2017. Available from: http:// wwwaifa.gov.it/sites/default/files/Rapporto_OsMed_2017_AIFA.pdf.

18. Bharmal MF, Weiner M, Sands LP, Xu H, Craig BA, Thomas J. Impact of patient selection criteria on prevalence estimates and prevalence of diagnosed dementia in a medicaid population. Alzheimer Dis Assoc Disord. 2007;21(2):92-100. doi:10.1097/WAD.0b013e31805c0835

19. Francesconi P, Gini R, Roti L, Bartolacci S, Corsi A, Buiatti E. The tuscany experimental registry for Alzheimer's disease and other dementias: how many demented people does in capture? Aging Clin Exp Res. 2007;19(5):390-393. doi:10.1007/BF03324719

20. Barnes TR, Banerjee S, Collins N, Treloar A, McIntyre SM, Paton C. Antipsychotics in dementia: prevalence and quality of antipsychotic drug prescribing in UK mental health services. $\mathrm{Br} J$ Psychiatry. 2012;201(3):221-226. doi:10.1192/bjp.bp.111.107631

21. Boucherie Q, Gentile G, Chalançon C, et al. Long-term use of antipsychotics in community-dwelling dementia patients: prevalence and profile accounting for unobservable time bias because of hospitalization. Int Clin Psychopharmacol. 2017;32(1):13-19. doi:10.1097/YIC.0000000000000150
22. Kirkham J, Sherman C, Velkers C, et al. Antipsychotic use in dementia is there a problem and are there solutions? Can J Psychiatry. 2017;62(3):170-181. doi:10.1177/0706743716673321

23. Dennis M, Shine L, John A, et al. Risk of adverse outcomes for older people with dementia prescribed antipsychotic medication: a population based e-cohort study. Neurol Ther. 2017;6(1):57-77. doi:10.1007/s40120-016-0060-6

24. Ralph SJ, Espinet AJ. Increased all-cause mortality by antipsychotic drugs: updated review and meta-analysis in dementia and general mental health care. J Alzheimers Dis Rep. 2018;2(1):1-26. doi:10.3233/ADR-170042

25. Koponen M, Taipalea H, Tanskanend A, et al. Long-term use of antipsychotics among community-dwelling persons with Alzheimer's disease: a nation wide register-based study. Eur Neuropsychopharmacol. 2015;25(10):1706-1713. doi:10.1016/j.euroneuro.2015.07.008

26. Puyat JA, Law MR, Wong ST, Sutherland JM, Morgan SG, Essential T. Potentially inappropriate use of antipsychotics across income groups: an analysis of linked administrative data. Can J Psychiatry. 2012;57(8):488-495. doi:10.1177/070674371205700807

27. Vasudev A. Trends in psychotropic dispensing among older adults with dementia living in longterm care facilities: 2004-2013. Am J Geriatr Psychiatry. 2016. doi:10.1016/j.jagp.2015.07.001.

28. Maguire A, Hughes C, Cardwell C, O’Reilly D. Psychotropic medications and the transition into care: a national data linkage study. $J$ Am Geriatr Soc. 2013;61:215-221. doi:10.1111/jgs.2013.61.issue-2

29. Trifirò G, Spina E, Brignoli O, Sessa E, Caputi AP, Mazzaglia G. Antipsychotic prescribing pattern among Italian general practitioners: a population-based study during the years 1999-2002. Eur J Clin Pharmacol. 2005;61(1):47-53. doi:10.1007/s00228-004-0868-3

30. Chiu YW, Huang CW, Chena PJ, et al. Trends and factors associated with antipsychotic use among elderly patients with dementia in Taiwan from 2005 to 2013: a population-based study. Int Clin Psychopharmacol. 2017;32(5):262-270. doi:10.1097/YIC.0000000000000181

31. Wattmo C, Londos E, Minthon L. Solitary living in Alzheimer's disease over 3 years: association between cognitive and functional impairment and community-based services. Clin Interv Aging. 2014;9:1951-1962. doi:10.2147/CIA.S71709

32. Xiong GL, Filshtein T, Beckett LA, Hinton L. Antipsychotic use in a diverse population with dementia: a retrospective review of the National Alzheimer's coordinating center database. $J$ Neuropsychiatry Clin Neurosci. 2015;27:326-332. doi:10.1176/appi. neuropsych. 15010020

33. Kim S, Choi H, Yoo J, Kim S, Kim BS, Won C. Factors correlated with initiating antipsychotics among dementia patients in Korean long-term care facilities: National Health Insurance service-senior cohort (2002-2013). J Clin Gerontol Geriatrics. 2017;8(4):114-122.

34. Trenaman SC, Rideout M, Andrew MK. Sex and gender differences in polypharmacy in persons with dementia: a scoping review. $S A G E$ Open Med. 2019;7:1-10. doi:10.1177/2050312119845715

35. Kales HC, Zivin K, Kim HM, et al. Trends in antipsychotic use in dementia 1999-2007. Arch Gen Psychiatry. 2011;68(2):190-197. doi:10.1001/archgenpsychiatry.2010.200

36. Stocks JS, Kontopantelis E, Webb RT, Avery AJ, Burns A, Ashcroft DM. Antipsychotic prescribing to patients diagnosed with dementia without a diagnosis of psychosis in the context of national guidance and drug safety warnings: longitudinal study in UK general practice. Drug Saf. 2017;40(8):679-692. doi:10.1007/s40264-017-0538-x

37. Wastesson JW, Ringbäck Weitoft G, Johnell K. Educational disparities in antipsychotic drug use among older people with and without dementia in Sweden. Acta Psychiatr Scand. 2015;132(1):20-28. doi:10.1111/acps.2015.132.issue-1

38. Sivananthan SN, Lavergne MR, McGrail KM. Caring for dementia: a population-based study examining variations in guideline-consistent medical care. Alzheimers Dement. 2015;11(8):906-916. doi:10.1016/ j.jalz.2015.02.008 
39. Bunn F, Burn AM, Goodman C, et al. Comorbidity and dementia: a scoping review of the literature. BMC Med. 2014;12:192-207. doi:10.1186/s12916-014-0192-4

40. Clague F, Mercer SW, Mclean G, Reynish E, Guthrie B. Comorbidity and polypharmacy in people with dementia: insights from a large, population-based cross-sectional analysis of primary care data. Age Ageing. 2017;46(1):33-39. doi:10.1093/ageing/afw176
41. Bagnall AM, Jones L, Ginnelly L, et al. A systematic review of atypical antipsychotic drugs in schizophrenia. Health Technol Assess. 2003;7(13):1-193. doi:10.3310/hta7130
Clinical Interventions in Aging

\section{Publish your work in this journal}

Clinical Interventions in Aging is an international, peer-reviewed journal focusing on evidence-based reports on the value or lack thereof of treatments intended to prevent or delay the onset of maladaptive correlates of aging in human beings. This journal is indexed on PubMed Central, MedLine, CAS, Scopus and the Elsevie

Submit your manuscript here: https://www.dovepress.com/clinical-interventions-in-aging-journal
Dovepress

Bibliographic databases. The manuscript management system is completely online and includes a very quick and fair peer-review system, which is all easy to use. Visit http://www.dovepress.com/ testimonials.php to read real quotes from published authors. 